\title{
Jornadas de Arquitectura y Cooperación al Desarrollo
}

\author{
Esteban de Manuel Jerez*
}

\section{Manuel J. Martín Hernández**}

\section{Resumen}

La Escuela Técnica Superior de Arquitectura de Sevilla ha organizado unas jornadas internacionales sobre Arquitectura y Cooperación al Desarrollo los días 21 y 22 de octubre de 2010. En ellas se han dado cita personas de referencia nacional e internacional pertenecientes a las agencias de cooperación española y andaluza, de la Dirección General de Arquitectura de la Junta de Andalucía, del mundo universitario y de las ONG del sector del hábitat. Las Jornadas han servido para crear de una red de Escuelas de Arquitectura españolas que tendrá por objetivo impulsar la cooperación internacional al desarrollo desde la universidad, en investigación, docencia y extensión universitaria, a través de la participación en proyectos sobre el terreno, en colaboración con las agencias de cooperación y las ONG.

\section{Palabras clave}

Hábitat; Cooperación; Desarrollo; Arquitectura; Formación e investigación.

\section{Abstract: Conference on Architecture and Development Cooperation}

The School of Architecture of Seville held an international conference on Architecture and Development Cooperation on 21 and 22 October, 2010. Members of national and international renown were invited from Andalusian and Spanish cooperation agencies, from the Department of Architecture of the Junta de Andalucía, from academia, and from NGO of the habitat sector. The conference helped create a network of Spanish Schools of Architecture whose aim is to promote international development cooperation from the university, in research, teaching and continuing university education through participation in field projects in collaboration with cooperation agencies and NGO.

\section{Key words}

Habitat; Cooperation; Development; Architecture; Training and Research.

\footnotetext{
* Profesor Titular de Universidad. Escuela Técnica Superior de Arquitectura (ETSA), Universidad de Sevilla. Avda. Reina Mercedes, no 2. 41013 Sevilla. E-mail: edemanuel@us.es.

${ }_{*}^{*}$ Datos de contacto: Escuela de Arquitectura de Las Palmas. Campus de Tafira. 35017 Las Palmas de Gran Canaria. E-mail: mmartin@dact.ulpgc.es.
} 
En el mundo actual más de mil millones de personas viven en condiciones precarias, en tugurios, favelas, bidonvilles... en viviendas deficientes, sin acceso a servicios básicos como el agua o la electricidad, en condiciones de extrema vulnerabilidad ante movimientos sísmicos o fenómenos atmosféricos. Naciones Unidas, a través de la comisión UN-HABITAT, quiere hacer frente a estos retos y dedica la primera semana de octubre a reflexionar sobre el estado de la cuestión y sensibilizar a la población para conseguir la voluntad política necesaria para dar solución a estos problemas. Tras dos conferencias Mundiales del Hábitat (Vancouver 1976, Estambul 1996) y numerosos encuentros y conferencias nacionales, podemos concluir que, pese a ciertos avances, la magnitud del problema sigue siendo enorme y la voluntad política para afrontarlo aún débil. Los objetivos de milenio se plantean como meta reducir en cien millones los mil millones de habitantes que viven en chabolas. Es un paso claramente insuficiente.

Ante este contexto, ¿qué respuestas podemos dar a estos retos sociales desde la arquitectura, y más específicamente, desde las escuelas de arquitectura?

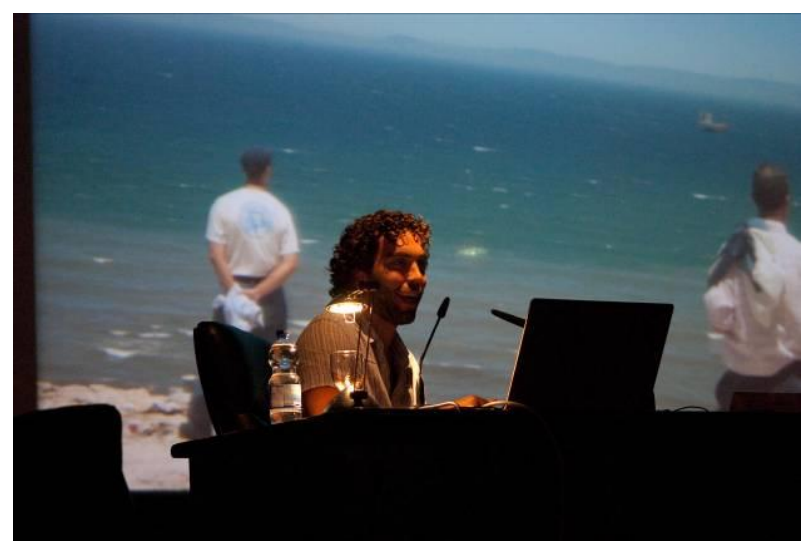

Entendemos que como universitarios y profesionales estas cuestiones no sólo no deben sernos ajenas sino que deberían tener un lugar prioritario entre nuestras preocupaciones. La universidad, consciente de que debe estar atenta a las necesidades sociales de su tiempo, empieza en los últimos años a abrir un hueco a la cooperación internacional al desarrollo y a crear estructuras adecuadas para ello, de modo que pueda aprovecharse su potencial de construcción de conocimiento, educación y transferencia en este campo. En el dominio de la arquitectura, como en otros, surgen líneas de investigación, docencia y transferencia de conocimiento vinculadas a la cooperación internacional al desarrollo. Así encontramos que la Junta de Andalucía fue pionera en nuestro país al crear en 1988 su programa de cooperación internacional desde la Dirección General de Arquitectura. Posteriormente el Ministerio de Asuntos Exteriores impulsó en 1992 el Programa CYTED (Ciencia y Tecnología para el Desarrollo), dentro del cual se insertó el programa XIV de vivienda de interés social, que impulsó la creación de redes de cooperación y programas de investigación latinoamericanos en este campo. En paralelo en América Latina surgieron redes educativas como ULACAV (Unión Latinoamericana de Cátedras de Vivienda), que en octubre pasado celebró su XVI Edición en Montevideo, en las que se impulsa la introducción de asignaturas de grado y de postgrado, interdisciplinares, vinculadas a la producción social del hábitat, en las que se han venido formando arquitectos y trabajadores sociales para especializarse en esta materia. Por otra parte se han constituido redes sociales de ONGs de profesionales y entidades cívicas, articuladas en torno a HIC (Coalición Internacional del Hábitat), que han tenido por objeto la lucha por el derecho a la vivienda y a la ciudad. Todo esto nos habla de un panorama en el que arquitectos y otros profesionales vienen desde los años 70 trabajando en desarrollar conceptos, métodos, marcos teóricos y estrategias de acción desde los que abordar el derecho a la vivienda y a la ciudad. Uno de los con- 
ceptos desarrollados es el de la necesidad de adecuar las tecnologías al contexto (tecnologías apropiadas) y las necesidades de los habitantes, que en gran proporción son autoconstructores (tecnologías apropiables). A este esfuerzo se suman iniciativas de cooperación impulsadas por las Agencias Especializadas en Cooperación (AECID, AACID...), administraciones autonómicas, provinciales y locales, con programas pioneros como el impulsado por la Consejería de Obras Públicas y Vivienda, y multitud de ONG especializadas, como fundación CEAR, Arquitectos Sin Fronteras, Arquitectura y Compromiso Social, Ingeniería Sin Fronteras, etc.

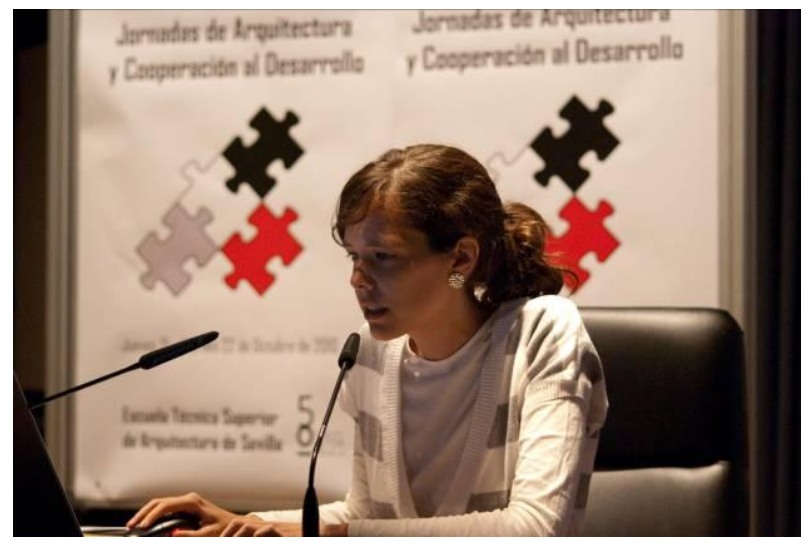

Con estos antecedentes, y conocedores de que en varias Escuelas de Arquitectura españolas están surgiendo iniciativas paralelas para introducir la cooperación al desarrollo en la docencia, la investigación y la extensión universitaria, la Escuela Técnica Superior de Arquitectura de Sevilla, con el decidido apoyo de la Junta de Andalucía, ha organizado durante los días 21 y 22 de octubre de 2010, unas "Jornadas de Arquitectura y Cooperación al Desarrollo" con el objetivo de, entre otros, reunir a una serie de personas interesadas provenientes del ámbito universitario, de administraciones públicas o de organizaciones de la sociedad civil, para escuchar sus experiencias y debatir sus ideas en torno a la cooperación al desarrollo en materia de arquitectura y hábitat. Se trataba así de provocar un encuentro entre escuelas de arquitectura, agencias de cooperación internacional y organizaciones no gubernamentales con vistas a la colaboración entre ellas para afrontar los retos del hábitat en el presente, todo ello a lo largo de los cuatro módulos en que se dividieron las jornadas. El primer módulo, "Retos del hábitat: La cooperación al desarrollo como respuesta", fijó el marco de los debates, a partir de las intervenciones de Manuel Iglesias-Caruncho y Ana Sugranyes. Algunas de las conclusiones que podríamos reseñar giran en torno a la insistencia en que el protagonista de todo el proceso deba ser siempre el país en desarrollo receptor de las ayudas, pues no solo conoce sus necesidades sino también sus aspiraciones; en ese sentido se procurará la eficacia de la cooperación buscando su convergencia y coherencia con otras políticas internas y externas de desarrollo. Es importante además realizar distinciones entre los países beneficiarios de ayudas, cuantificando debidamente sus límites y entendiendo las relaciones que deberían existir entre la eficacia de dichas ayudas y los problemas de gobernanza, evitando sobre todo donaciones destinadas a intereses ajenos al propio desarrollo.

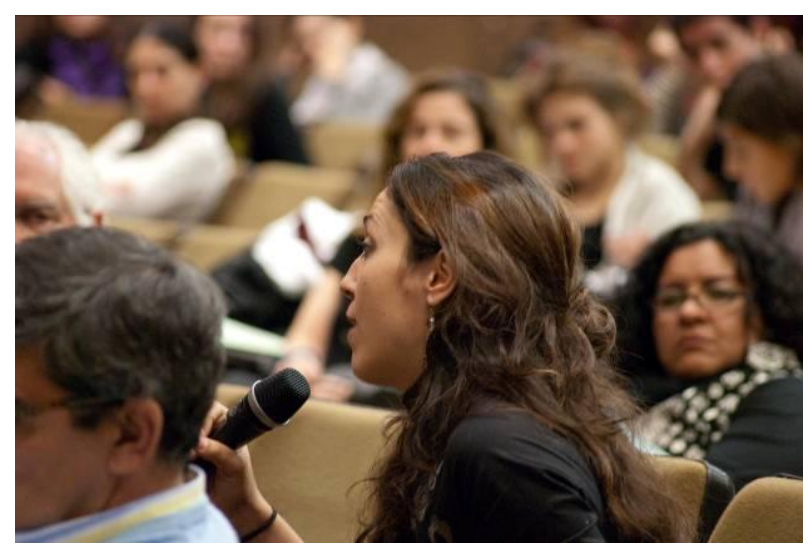

Por otro lado, si los retos a que se refiere el título de este primer debate implicaran una gestión social del hábitat, esto significaría realizar lecturas de la realidad desde la complejidad que suponen las múltiples miradas políticas, civiles o económicas 
realizadas desde los pueblos protagonistas de estos procesos, destinadas a redefinir la gestión colectiva del territorio o el derecho a la ciudad, como modos de canalizar y administrar de una forma más efectiva las ayudas y su propio desarrollo.

En el segundo módulo, y a partir de las reflexiones de Luis González Tamarit, se leyeron una serie de comunicaciones en torno a diversas "experiencias en cooperación sobre el terreno". Se hizo así evidente el modo como la cooperación internacional abarca un amplio abanico de actividades que van de la acción concreta en la producción de nuevos hábitats a la intervención sobre el patrimonio (entendiendo este concepto en su acepción más amplia como todo lo construido y no solo lo históricoartístico), pasando por procesos de formación y difusión, fomento y gestión de los múltiples procesos a que dan lugar estas experiencias. Los invitados a la mesa redonda posterior fueron convocados para tratar de la posible colaboración entre Agencias de Cooperación, Universidades y ONG. Como conclusión, y ante la hipótesis de normar o reglamentar dicha colaboración, el encendido debate derivó a que el encuentro -si se produjerase desarrollara del modo más natural posible, sin imposiciones que desactivaran procesos de por sí complejos y a veces desazonadores.

El tercer módulo giró en torno a la "formación para la cooperación al desarrollo en hábitat y arquitectura", siendo Pedro Lorenzo Gálligo quien estableció en su conferencia-marco las diversas estrategias de una doble formación, tanto para el hábitat como para la cooperación al desarrollo. Entendiendo el hábitat, por tanto, como motor de desarrollo, su producción social autogestionada implicaría la necesaria formación no solo de quienes cooperan sino también de quienes reciben las ayudas, una preparación, por lo tanto, de técnicos, administradores y usuarios, capacitados así para la gestión, la organización o la resolución tecnológica y económica de los problemas del hábitat. En cualquier caso, como se insistió más de una vez, no se aprendería a cooperar sin cooperar.

Planteando temas como la necesidad de aprender a trabajar con el otro, o que el sur y el norte no son realidades que se puedan abordar desde las mismas estrategias, se hablaba aquí de un nuevo paradigma al que las escuelas de arquitectura españolas no están acostumbradas. Dicho paradigma tiene que ver con el trabajo en situaciones complejas donde hay que aprender, sobre todo, a diseñar procesos, y no tanto productos. Este fue el tema de discusión en algunas comunicaciones y en la posterior mesa redonda, donde se destacó la necesidad de, al menos, "abrir una puerta" en la Universidad a la sensibilización en estos temas, y, decididamente, de la conveniencia de una determinada profesionalización de postgrado para los técnicos interesados en estos procesos. En ese sentido, y ante la realidad de que en algunas escuelas de arquitectura se intenta, no sin cierta oposición, desarrollar trabajos de curso e incluso de fin de carrera en torno al hábitat y el desarrollo o a la arquitectura como proceso, es por lo que se llegó a proponer una gestión unitaria de estos temas para todas las escuelas interesadas y el fomento de una red específica de colaboración.

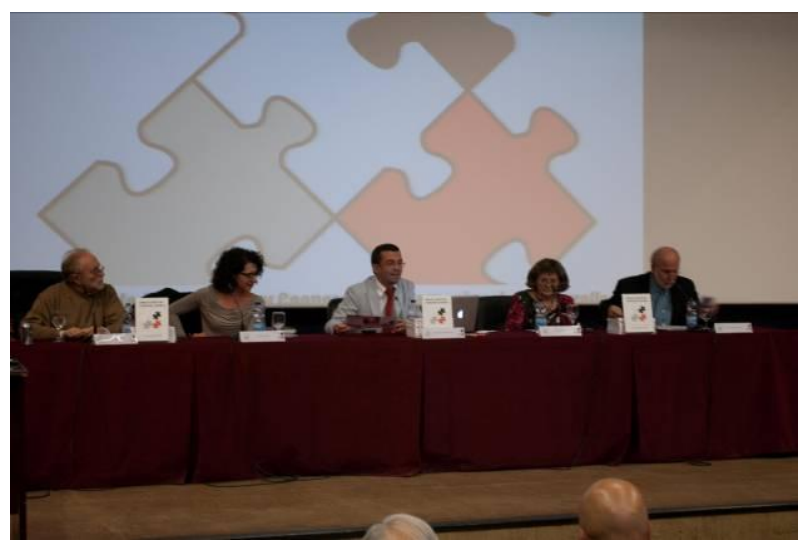

El cuarto módulo sirvió para preguntarnos acerca de la "investigación socialmente necesaria en materia de hábitat", siendo Julián Salas Serrano quién realizó las reflexiones necesarias a partir de 
su experiencia en la coordinación del subprograma "Vivienda de Interés Social" dentro del Programa CYTED. Nos expuso así las múltiples tecnologías de alta cualidad arquitectónica que nos permiten apuntar hasta qué punto es importante para nosotros aprender a aprender de lo que se hace en otros lugares, desde desarrollos de investigaciónacción que llamaríamos también cooperación sur-sur, y evitando de paso cierto colonialismo que Sugranyes llegó a apreciar en algunas intervenciones a lo largo de las Jornadas.

Por ello, se insistió en que la investigación debería ser multidisciplinar y colectiva, interviniendo todas las partes en la misma red a que se aludió hablando de la formación. Desgraciadamente, hubo coincidencia en la mesa redonda final en que, en relación con la pregunta de “¿qué investigación es necesaria para impulsar el desarrollo de los asentamientos humanos?", los temas posibles no se incluían aún en los catálogos de temas prioritarios o de excelencia. En cualquier caso, y a pesar de todo, se trataría de adaptar las metodologías de investigación en estos campos a los procedimientos normales en cualquier centro de I+D, solicitando que los temas propios sean incluidos en aquellos catálogos de prioridad. No hay que olvidar tampoco, como no se dejó de insistir, que durante los procesos de investigación estaremos también aprendiendo tecnologías, recursos e instrumentos capaces de ser aplicados aquí.

Como conclusión final deberíamos volver a la mesa redonda con que se cerraba el primer módulo de las Jornadas y recordar su título: “¿Por qué, pa- ra qué y cómo cooperar en materia de hábitat y arquitectura?" La respuesta a la tercera pregunta se fue contestando a lo largo de las conferencias, comunicaciones y debates de los módulos restantes. Pero a la vista de lo tratado en las Jornadas, la mejor respuesta a las dos primeras seguramente sería: para aprender nosotros mismos a habitar. La principal implicación de estas jornadas ha sido el fortalecimiento de vínculos entre profesores, investigadores y grupos de cooperación al desarrollo de las Escuelas de Arquitectura de Las Palmas de Gran Canaria, Madrid, Barcelona, La Coruña, VaIladolid, San Sebastián, Valencia y Sevilla. Un primer objetivo de esta red va a ser impulsar la creación de tribunales específicos de Proyectos de Fin de Carrera que aborden la temática de la Cooperación al Desarrollo, en el ámbito local e internacional. Un segundo objetivo será la organización en las Palmas de Gran Canarias de un congreso internacional sobre esta materia.

\section{Referencias}

OBITER. Actos y Eventos de la Escuela Técnica Superior de Arquitectura. Universidad de Sevilla. $<$ http://obiter.us.es/index.php?option=com_seyret \&ltemid $=2 \&$ catid $=40>$.

\section{Cita del artículo:}

DE MANUEL JEREZ, Esteban y MARTíN HERNÁNDEZ, Manuel J. Jornadas de Arquitectura y Cooperación al Desarrollo. Hábitat y Sociedad, 2010, no 1, p. 175-179. $<$ www.habitatysociedad.us.es $>$. 